tion coefficient revealed a definite trend in this influence. These factors are, in $\mathrm{MZ}$ families, the increase in father's age, the use of contraceptives by the mother, the improvement of nutrition; and, in DZ families, the increase in mother's height, the deterioration of family relations, and mother's manual work.

Prof. R. P. Martynova, Institute of Cytology and Genetics, Siberian Branch of the Academy of Sciences, Novosibirsk 63009o, USSR

\section{DELAYED OVULATION AND MONOZYGOTIC TWINNING IN THE RABBIT}

\section{ONDINE BOMSEL-HELMREICH}

Central Station of Animal Physiology, Jouy-en-Josas, France

The following investigations on the quality of the mammalian egg have demonstrated that delayed ovulation may induce $\mathrm{MZ}$ twinning. We delayed experimentally ovulation in the rabbit: follicular maturation was induced by a small quantity of PMSG (Pregnant Mare Serum Gonadotropin, I6 UI four times); coitus, which induces ovulation in the rabbit, was delayed 60 hours after the last injection. From 387 blastocysts obtained after this treatment, 6 (I.5\%) were pairs of $M Z$ twins, twinning being otherwise exceptional in the rabbit. Other anomalies of the embryos appeared as well and seem to be related to a deficiency of quality of the eggs: high embryonic mortality $(62 \%$ vs. $27 \%$ in controls $)$ and chromosomal anomalies $(20 \%)$ such as trisomies, triploidies, and chimaeras. The relation between MZ twinning, chromosomal anomalies and embryonic mortality induced by delayed ovulation, could be connected and compared with the bad perinatal results frequently observed in human $\mathrm{MZ}$ twins.

Dr. O. Bomsel-Helmreich, Station Centrale de Physiologie Animale, INRA, $7^{8} 35^{\circ}$ Jouy-en-Josas, France

\section{TRIPLET PREGNANCY \\ AFTER TREATMENT WITH CLOMIPHENE ACETATE IN A SUBFERTILE WOMAN}

\section{PEZZANI}

Department of Obstetrics and Gynecology, General Hospital, Ceprano, Frosinone, Italy

A 26-year-old subfertile woman with a history of abortions at the seventh-ninth week was treated with Glomid, $50 \mathrm{mg}$ for 5 days. A pregnancy resulted, which ended in the premature birth of a set of alive triplets that sex and blood-group determinations showed to be trizygotic.

It is suggested that this production of a multiple ovulation in a woman with luteal deficiency be the result of excessive dosage of Clomid.

Prof. Massimino Pezzani, Via Caragno Vecchia 2, Ceprano, Frosinone, Italy 